\title{
SSSPP Position paper: Physical activity and mental health
}

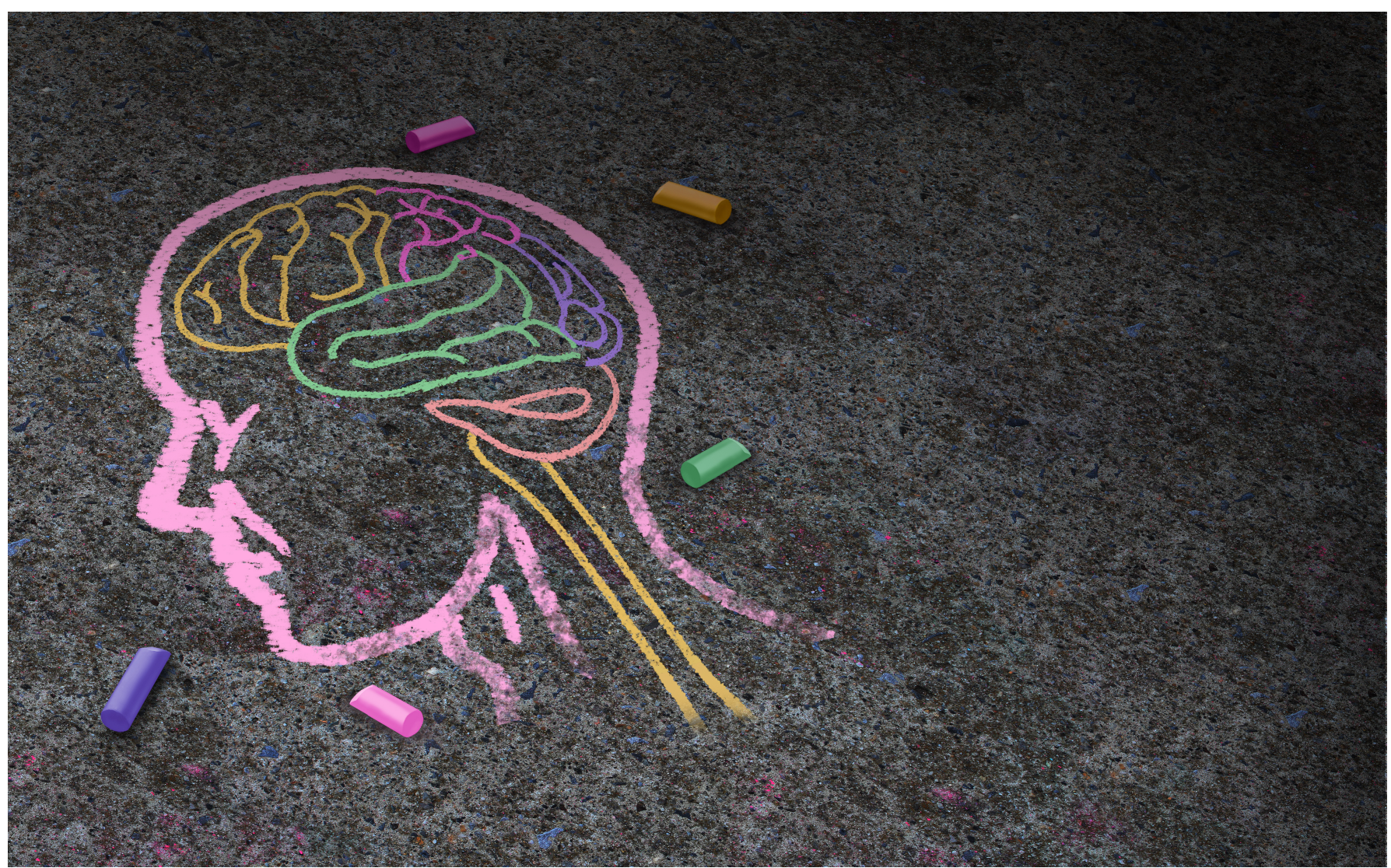

by Swiss Society for Sports Psychiatry and Psychotherapy SSSPP

Imboden Christian ${ }^{1}$, Claussen Malte Christian ${ }^{2}$, Gerber Markus ${ }^{3}$, Gonzalez Hofmann Carlos ${ }^{4}$,

Hemmeter Ulrich ${ }^{5}$, Seifritz Erich $^{6}$

${ }^{1}$ Private Clinic Wyss AG, Münchenbuchsee, Switzerland

${ }^{2}$ Department of Psychiatry, Psychotherapy and Psychosomatics, University Hospital of Psychiatry Zurich, Zurich, Switzerland, Private Clinic Wyss AG, Münchenbuchsee and Psychiatric Services Grisons, Chur, Switzerland

${ }^{3}$ Department of Sport, Exercise and Health, University of Basel, Switzerland

${ }^{4}$ Practice for Psychiatry and Psychotherapy, Romanshorn, Switzerland 
${ }^{5}$ Department for Geriatric Psychiatry and Psychotherapy, Psychiatry St. Gallen North, Wil, Switzerland

${ }^{6}$ Department of Psychiatry, Psychotherapy and Psychosomatics, University Hospital of Psychiatry Zurich

\section{Abstract}

Promoting physical activity (PA) has not yet been established as a standard procedure in psychiatric care. Psychiatric patients are at higher chance to be physically inactive which contributes to increased morbidity and mortality. Regular PA has shown to improve mental wellbeing in the general population and reduce the risk to develop several mental disorders. Assessing PA and motivation for change should be established as routine in psychiatric practice. The recommended dose of exercise for optimal health benefits should be achieved and recommendations on exercise-prescription as well as coaching-programs tailored for mentally ill patients should be developed. Structured exercise therapies should become part of standard psychiatric care. A network of "mental health friendly" sports-clubs could help to facilitate PA for psychiatric populations. Public awareness of mental health benefits of exercise specifically in the prevention of mental disorders is an important topic addressed by the Swiss Society for Sports Psychiatry and Psychotherapy. This includes interdisciplinary and interprofessional coordination of efforts to bring more PA into mental health.

\section{Zusammenfassung}

Das Fördern von körperlicher Aktivität ist noch keine reguläre Methode in der psychiatrischen Praxis. Psychiatrische Patienten sind körperlich weniger aktiv, was wiederum zu einer erhöhten Morbidität und Mortalität mit beiträgt. Regelmässige Bewegung kann psychisches Wohlbefinden in der Allgemeinbevölkerung verbessern und reduziert das Risiko, verschiedene psychiatrische Erkrankungen zu entwickeln. Das Erfassen körperlicher Aktivität und diesbezüglicher Veränderungsmotivation sollte in der psychiatrischen Praxis Einzug halten. Es ist anzustreben, dass psychisch erkrankte Menschen die Bewegungsempfehlungen erreichen und diesbezüglich spezifische Coaching-Programme für psychisch kranke Menschen entwickelt werden. Strukturierte Sporttherapien sollten Teil der Strandardbehandlung in der Psychiatrie werden, dabei kann ein Netzwerk von «Psychiatrie-freundlichen» Sportvereinen helfen, körperliche Aktivität in psychiatrischen Populationen zu fördern. Die öffentliche Wahrnehmung psychischer Effekte von Sport, besonders in der Prävention psychischer Erkrankungen sowie das Fördern der interdisziplinären und interprofessionellen Koordination sind wichtige Ziele der Schweizerischen Gesellschaft für Sportpsychiatrie und -psychotherapie.

Promoting physical activity (PA) has not yet been established as a standard procedure in psychiatric care. Psychiatric patients are at higher chance to be physically inactive [1] which contributes to increased morbidity and mortality in psychiatric patients. [2,3] On the other hand, regular PA has shown to improve mental wellbeing in the general population [4] and reduce the risk to develop several mental disorders. This has been shown so far for depression [5], anxiety disorders [6], Insomnia [7] and even dementia [8). In addition, structured and supervised physical exercise might be an alternative or additional treatment strategy for depression [9], dementia [10], cognitive symptoms of schizophrenia [11] and maybe other psychiatric disorders such as anxiety disorders, substance use disorders and posttraumatic stress disorder. 
Considering the large body of evidence, recommendations to establish PA in psychiatric care have been published [12]. Since PA yields a broad array of mental and physical health benefits, it is high time to move it closer to the focus of treating physicians and treatment networks.

\section{Background}

At present, PA plays a role in inpatient treatment regimes. In Switzerland most clinics have already established therapies including physical activity (i.e. sports therapy, physiotherapy, body therapies, fareast techniques such as yoga and hippotherapy). However, in a survey conducted in n=55 Germanspeaking Swiss clinics, only $25 \%$ of patients participated in those programs [13]. A later study conducted at three psychiatric clinics in the German-speaking part of Switzerland with $n=107$ psychiatric inpatients, a total of 57\% met physical activity recommendations and 55\% participated in structured exercise and sport therapy activities. Those who took part in those programs were significantly more likely to meet recommended levels of PA than those not participating [14]. Establishing a treatment regime with aerobic exercise 3 times per week at moderate intensity levels in Swiss clinics is feasible for psychiatric inpatients suffering from depression, however dropout rates around 20\% might be a matter of concern [15]. In the future, motivational and volitional coaching programs specifically tailored for patients with psychiatric disorders might help to further improve PA levels in this population [16]. Such programs should be applicable in inpatient and outpatient settings.

\section{Problematic areas}

Considering the role of PA in prevention and treatment of mental disorders the following problem areas can be identified: 
Regular assessment of PA or physical fitness in patients with mental disorders has not yet been established in psychiatric practice. [17,18]

Standard procedures concerning the improvement of PA and physical fitness such as exercise-prescription for mental health or coaching-programs tailored to the specific needs of psychiatric patients are not part of treatment regimens. [16]

Despite the emerging evidence of its effectiveness, exercise prescription still plays an inferior role in treatment guidelines for mental disorders.

Still little is known about the most suitable physical activity and exercise regimens in terms of type, duration, intensity, and frequency. $[19,20]$

Although many clinics offer some sort of PA in their therapy-programs, there is still a lack of evidence-based exercise treatment regimens that are kept up for several weeks during the acute-phase of a mental disorder although clear recommendations are available. [12]

Transfer of acquired exercise routines into everyday life poses many obstacles that are not yet thoroughly addressed during inpatient treatment. [21]

While therapies involving some sort of PA are well established in psychiatric hospitals, the topic is not yet well addressed in the outpatient setting. There are little to no possibilities for psychiatric outpatients to participate in therapeutic structured exercise programs such as sports therapy, body therapy or therapeutic yoga. Financing of such treatment programs is very difficult to obtain. Nevertheless, evidence shows that lifestyle PA can be facilitated in this particular group via systematic counselling. [22]

For patients with mental disorders, it can be challenging to acquire a regular exercise routine within a supporting social environment. Taken together, PA activity barriers [23] and implicit attitudes towards PA and structured exercise programs [24] are still poorly understood in this specific population. Clubs performing popular sports are not yet suited well enough to fit the special circumstances and challenges that arise for people with mental health problems.

Financial support to facilitate personal PA plans is difficult to obtain. This is of special concern since the population with mental disorders is faced with lower financial possibilities due to higher rates of unemployment, social security and disability pension. [25]

While the general health-enhancing effects of exercise are well known to the general public, there is still an unmet need to publicly inform about effects of PA supporting mental health. This is mirrored in the fact that several organisations have published position statements supporting the role of PA in mental health. [12,26,27] 


\section{Interprofessional coordination}

Supporting an increased use of PA as a therapeutic and preventive agent involves several professions. General practitioners, sports and exercise physicians and psychiatrists, sports psychologists and sport and exercise scientists should not only develop techniques to assess PA levels of patients with mental disorders and offer specified exercise prescriptions. They are also required to be informed about the local network of exercise facilities, clubs and organizations as well as have access to specialized exercise coaches for mental health. In order to achieve this, cooperation is needed with other professions such as physiotherapists, sports therapists and body therapists. Psychiatric nurses may also play an important role in motivating patients to increase PA and support them to implement activities in order to reach individual goals considering PA. Sports and exercise scientists and/or clinical psychologists may support patients with motivational techniques to change their physical activity behavior and with volitional techniques to sustain achieved change over a longer period of time.

\section{Approaches}


Assessing PA and motivation for change should become a routine in psychiatric practice. Tools such as the Simple Physical Activity Questionnaire (SIMPAQ] [28], the short form of the International Physical Activity Questionnaire (IPAQ) [29] or other suitable physical activity questionnaires [30] should be propagated and made widely available for clinicians in Switzerland.

Achieving at least the recommended dose of exercise for optimal health benefits (weekly 2.5 hours moderate OR 1.25 hours vigorous exercise OR any combination of the two] should be aimed at in psychiatric populations. [31,32] However, it is likely that beneficial effects on mental health can already appear with lower doses. [33]

Recommendations on exercise-prescription for patients with mental disorders should be developed nationally and made available for treating physicians. They should also include motivational techniques to improve and sustain motivation for change in primarily sedentary patients. If regular PA or exercise training is not maintained over longer periods of time, the achieved effects might disappear. $[34,35]$

Recommendations should also include evidence-based training-regimens that have proved to be effective for distinct diagnoses and symptoms.

Methodically robust research on the effects of exercise interventions is still needed to reach higher recommendation levels for exercise in treatment guidelines for depression and schizophrenia. Simultaneously, authors of national guidelines should be sensitized for the topic of physical fitness and its importance in mental health.

Structured exercise therapies for outpatients should be developed and established as part of standard psychiatric outpatient care. A focus should be placed on testing cost-effectiveness of these programs. [36] At the same time financing of such therapies by health insurance companies should be secured. Moreover, the potential of digitally guided and remote training programs should be used more systematically.

A network of gymnastics- and other sports-clubs that are "mental health friendly" could help to facilitate access to sport activities for people with mental disorders. Ideally such clubs have the possibilities to support people with low incomes in order to make activities financially more accessible. At the same time existing group activities for people with mental disorders (such as those offered in Switzerland by PluSport) should be supported and strengthened.

Coaching-programs to enhance physical activity by setting individual goals and support participants to achieve those specifically tailored for patients with mental disorders should be developed and tested for efficacy. Accordingly, there is a great need for well-trained physical activity facilitators. In Switzerland, there are already training courses at the University of Basel (https://advancedstudies.unibas.ch/ studienangebot/kurs/cas-personal-health-coach-238755] and at the University of Bern (https://svgs.ch/wp-content/uploads/2019/01/ broschuere-cas-psy_2019.pdf), in which in-depth knowledge and practical skills can be acquired.

Public awareness of the mental health benefits of exercise specifically in the prevention of mental disorders should be raised by addressing this topic through various canals and methods. 


\section{Recommendations}

Our main recommendations can be linked directly to the proposed starting points. The Swiss Society for Sports Psychiatry and Psychotherapy SSSPP is ready to take a coordinating role in the efforts to achieve those goals in close collaboration with other professional societies (such as the Swiss Society for Sports Medicine, the Swiss Society of Sport Science, universities and psychiatric institutions located in Switzerland) [see box]. The society will offer regular symposia and courses as part of the ongoing formation of psychiatrists, sports physicians and general practitioners focusing on the importance of PA for mental health and will coordinate the development of implementable recommendations on the assessment of PA and exercise-prescription in daily practice. The initiative "Exercise is Medicine" (exerciseismedicine.org) by the American College of Sports Medicine can act as a good example on how to establish awareness about the importance of PA for general health benefits including mental health. The SSSPP will lobby for the implementation of sports psychiatry related topics at the university level for medical students and in the formation (postgraduate curricula) of residents. At the same time a structured program for psychiatrists wishing to obtain a specialty for sports psychiatry will focus on mental health in elite athletes, as well as physical activity and mental health. [37,38]

Networking with clubs and other institutions offering sports for people with mental disorders (such as PluSport) will be another important topic for the SSSPP, aiming at better access to popular sports for mentally handicapped persons.

Clinical research on the effects of PA in mental health and evaluation of programs aiming at improvement of PA in psychiatric patients will be supported by the SSSPP. Support may take part on methodological, clinical and by obtaining funding sources on a financial level. Last but not least, the SSSPP will engage itself in public awareness programs on the benefits of PA for mental health.

Taken together those proposed steps should enhance mental health in the general population and sensitize the various medical and paramedical disciplines involved in the treatment of patients with mental disorders to the abovementioned topics in order to increase physical fitness of psychiatric patients and therefore improve psychiatric treatment quality. 
The purpose of the SSSPP is to promote sports psychiatry and psychotherapy over the lifespan in Switzerland, in competitive sports and in the general population. This results in the following two areas of activity: 1. Mental health in competitive sports; 2 . Physical activity in the prevention and therapy of mental disorders.

Further information on the activities of the SGSPP can be found at: www.sgspp.ch

\section{Corresponding author}

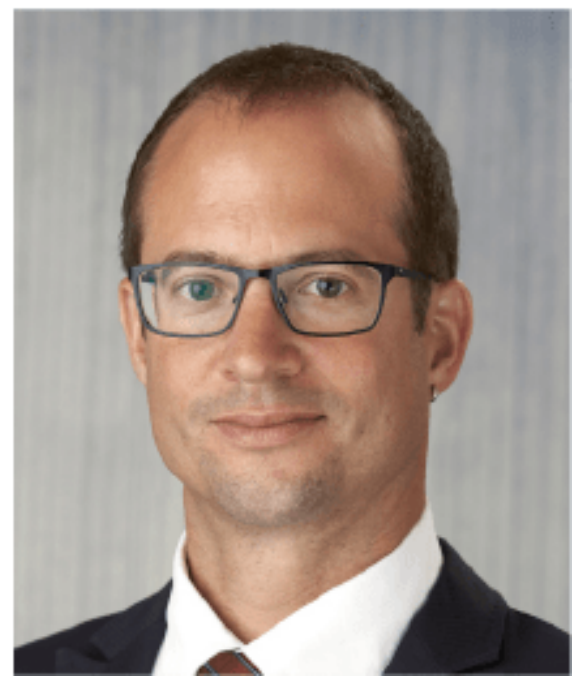

Dr. med. Christian Imboden

EMBA, Private Clinic Wyss AG

Münchenbuchsee, Switzerland

christian.imboden@pkwyss.ch

\section{References}

1. Vancampfort D, Firth J, Schuch FB, Rosenbaum S, Mugisha J, Hallgren M, et al. Sedentary behavior and physical activity levels in people with schizophrenia, bipolar disorder and major depressive disorder: a global systematic review and meta-analysis. World Psychiatry. 2017;16(3):308-15.

2. Murray CJL, Lopez AD. Global mortality, disability, and the contribution of risk factors: Global 
burden of disease study. Lancet. 1997;349:1436-42.

3. Walker ER, McGee RE, Druss BG. Mortality in mental disorders and global disease burden implications: A systematic review and meta-analysis. JAMA Psychiatry. 2015;72:334-41.

4. Chekroud SR, Gueorguieva R, Zheutlin AB, Paulus M, Krumholz HM, Krystal, J.H., et al. Association between physical exercise and mental health in 1.2 million individuals in the USA between 2011 and 2015: a cross-sectional study. Lancet Psychiatry. 2018;5:739-46.

5. Schuch FB, Vancampfort D, Firth J, Rosenbaum S, Ward PB, Silva ES, et al. Physical Activity and Incident Depression: A Meta-Analysis of Prospective Cohort Studies. Am J Psychiatry. 2018:appiajp201817111194.

6. Schuch FB, Stubbs B, Meyer J, Heissel A, Zech P, Vancampfort D, et al. Physical activity protects from incident anxiety: A meta-analysis of prospective cohort studies. Depress Anxiety. 2019;36(9):846-58.

7. Tsunoda K, Kitano N, Kai Y, Uchida K, Kuchiki T, Okura T, et al. Prospective study of physical activity and sleep in middle-aged and older adults. Am J Prev Med. 2015;48(6):662-73.

8. Buchman AS, Boyle PA, Yu L, Shah RC, Wilson RS, Bennett DA. Total daily physical activity and the risk of AD and cognitive decline in older adults. Neurology. 2012;78(17):1323-9.

9. Morres ID, Hatzigeorgiadis A, Stathi A, Comoutos N, Arpin-Cribbie C, Krommidas C, et al. Aerobic exercise for adult patients with major depressive disorder in mental health services: A systematic review and meta-analysis. Depress Anxiety. 2019;36(1):39-53.

10. Groot C, Hooghiemstra AM, Raijmakers PG, van Berckel BN, Scheltens P, Scherder EJ, et al. The effect of physical activity on cognitive function in patients with dementia: A meta-analysis of randomized control trials. Ageing Res Rev. 2016;25:13-23.

11. Firth J, Stubbs B, Rosenbaum S, Vancampfort D, Malchow B, Schuch F, et al. Aerobic Exercise Improves Cognitive Functioning in People With Schizophrenia: A Systematic Review and MetaAnalysis. Schizophr Bull. 2017;43(3):546-56.

12. Stubbs B, Vancampfort D, Hallgren M, Firth J, Veronese N, Solmi M, et al. EPA guidance on physical activity as a treatment for severe mental illness: A meta-review of the evidence and Position Statement from the European Psychiatric Association (EPA), supported by the International Organization of Physical Therapists in Mental Health (IOPTMH). European Psychiatry. 2018;54:124-44.

13. Brand S, Colledge F, Beeler N, Pühse U, Kalak N, Sadeghi Bahmani D, et al. The current state of physical activity and exercise programs in German-speaking, Swiss psychiatric hospitals: Results from a brief online survey. Neuropsychiatric Disease and Treatment. 2016;12:1309-17.

14. Ehrbar J, Brand S, Colledge F, Donath L, Egger ST, Hatzinger M, et al. Psychiatric in-patients are more likely to meet recommended levels of health-enhancing physical activity if they engage in exercise and sport therapy programs. Frontiers in Psychiatry. 2018;9:doi:10.3389/fpsyt.2018.00322.

15. Imboden C, Gerber M, Beck J, Eckert A, Puhse U, Holsboer-Trachsler E, et al. Effects of Aerobic Exercise as Add-On Treatment for Inpatients With Moderate to Severe Depression on Depression Severity, Sleep, Cognition, Psychological Well-Being, and Biomarkers: Study Protocol, Description of Study Population, and Manipulation Check. Front Psychiatry. 2019;10:262.

16. Gerber M, Beck J, Brand S, Cody R, Donath L, Eckert A, et al. The impact of lifestyle Physical Activity Counselling in IN-PATients with major depressive disorders on physical activity, cardiorespiratory fitness, depression, and cardiovascular health risk markers: study protocol for a randomized controlled trial. Trials. 2019;20(1):367.

17. Gerber M, Minghetti A, Beck J, Zahner L, Donath L. Is improved fitness following a 12-week exercise program associated with decreased symptom severity, better wellbeing, and fewer sleep complaints in patients with major depressive disorders? A secondary analysis of a randomized controlled trial. Journal of psychiatric research. 2019;113:58-64.

18. Rosenbaum S, Morell R, Abdel-Baki A, Ahmadpanah M, Anilkumar TV, Baie L, et al. Assessing physical 
activity in people with mental illness: 23-country reliability and validity of the simple physical activity questionnaire (SIMPAQ). BMC Psychiatry. 2020;20(1):108.

19. Gerber M, Minghetti A, Beck J, Zahner L, Donath L. Sprint Interval Training and Continuous Aerobic Exercise Training Have Similar Effects on Exercise Motivation and Affective Responses to Exercise in Patients With Major Depressive Disorders: A Randomized Controlled Trial. Front Psychiatry. 2018;9:694.

20. Nebiker L, Lichtenstein E, Minghetti A, Zahner L, Gerber M, Faude O, et al. Moderating Effects of Exercise Duration and Intensity in Neuromuscular vs. Endurance Exercise Interventions for the Treatment of Depression: A Meta-Analytical Review. Front Psychiatry. 2018;9:305.

21. Gerber M, Holsboer-Trachsler E, Pühse U, Brand S. Exercise is medicine for patients with major depressive disorders. But only if the "pill" is taken! Neuropsychiatric Disease and Treatment. 2016;12:1977-81.

22. Chalder M, Wiles NJ, Campbell J, Hollinghurst SP, Haase AM, Taylor AH, et al. Facilitated physical activity as a treatment for depressed adults: randomised controlled trial. Bmj. 2012;344:e2758.

23. Krämer LV, Helmes AW, Bengel J. Understanding activity limitations in depression. European Psychologist. 2014.

24. Gerber M, Ehrbar J, Brand R, Antoniewicz F, Brand S, Colledge F, et al. Implicit attitudes towards exercise and physical activity behaviour among in-patients with psychiatric disorders. Mental Health and Physical Activity. 2018;15:71-7.

25. Fryers T, Melzer D, Jenkins R, Brugha T. The distribution of the common mental disorders: social inequalities in Europe. Clinical practice and epidemiology in mental health : CP \& EMH. 2005;1:14.

26. Peirce N, Lester C, Seth A, Turner P, The Sports and Exercise Psychiatry Special Interest Group of the Royal College of Psychiatrists. The Role of Physical Activity and Sport in Mental Health 2018 [Available from: https://www.fsem.ac.uk/position_statement/the-role-of-physical-activity-and-sport-in-mental-health/.

27. Public Health Australia Association. Physical Activity and Mental Health Policy Position Statement 2018 [Available from: https://www.phaa.net.au/documents/item/2818.

28. Rosenbaum S, Ward PB, International Working G. The Simple Physical Activity Questionnaire. The lancet Psychiatry. 2016;3(1):e1-e.

29. Craig CL, Marshall AL, Sjostrom M, Bauman AE, Booth ML, Ainsworth BE, et al. International physical activity questionnaire: 12-country reliability and validity. Medicine and science in sports and exercise. 2003;35(8):1381-95.

30. Nigg CR, Fuchs R, Gerber M, Jekauc D, Koch T, Krell-Roesch J, et al. Assessing physical activity through questionnaires-A consensus of best practices and future directions. Psychology of Sport and Exercise. 2020:101715.

31. Dunn AL, Trivedi MH, Kampert JB, Clark CG, Chambliss HO. Exercise treatment for depression. Efficacy and dose response. American Journal of Preventive Medicine. 2005;28:1-8.

32. Mota-Pereira J, Silverio J, Carvalho S, Ribeiro JC, Fonte D, Ramos J. Moderate exercise improves depression parameters in treatment-resistant patients with major depressive disorder. Journal of psychiatric research. 2011;45(8):1005-11.

33. Hallgren M, Vancampfort D, Stubbs B. Exercise is medicine for depression: even when the "pill" is small. Neuropsychiatric disease and treatment. 2016;12:2715-21.

34. Hoffman BM, Babyak MA, Craighead WE, Sherwood A, Doraiswamy PM, Coons MJ, et al. Exercise and pharmacotherapy in patients with major depression: one-year follow-up of the SMILE study. Psychosomatic medicine. 2011;73(2):127-33.

35. Lindegård A, Jonsdottir IH, Börjesson M, Lindwall M, Gerber M. Changes in mental health in compliers and non-compliers with physical activity recommendations in patients with stress-related exhaustion. BMC Psychiatry. 2015;15:doi:10.1186/s12888-015-0642-3. 
36. Chalder M, Wiles NJ, Campbell J, Hollinghurst SP, Searle A, Haase AM, et al. A pragmatic randomised controlled trial to evaluate the cost-effectiveness of a physical activity intervention as a treatment for depression: the treating depression with physical activity (TREAD) trial. Health Technol Assess. 2012;16(10):1-164, iii-iv.

37. Claussen MC, Imboden C, Seifritz E, Hemmeter U, Gonzalez Hofmann C. SGSPP Curriculum Sportpsychiatrie und -psychotherapie: Stufe 1. Swiss Arch Neurol Psychiatr Psychother. 2020;68(3):48-52.

38. Claussen MC, Imboden C, Seifritz E, Hemmeter U, Gonzalez Hofmann C. Swiss Society for Sports Psychiatry and Psychotherapy SSSPP. SSSPP Curriculum Sports Psychiatry And Psychotherapy: Level 1. Swiss Sports \& Exercise Medicine. 2020;68(3):48-52. 